ORIGINAL ARTICLE

\title{
Comparing the Effect of Spinal and General Anaesthesia for Pre- Eclamptic Mothers Who Underwent Caesarean Delivery in A Tertiary, Addis Ababa, Ethiopia
}

\author{
Adugna Aregawi ${ }^{*}$, Tsehay Terefe ${ }^{2}$, Wossenyeleh Admasu' ${ }^{1}$, Leulayehu Akalu ${ }^{1}$
}

\section{OPEN ACCESS}

Citation: Adugna A, Tsehay T, Wossenyeleh A., Leulayehu A. Comparing the Effect of Spinal and General Anaesthesia for Pre-Eclamptic Mothers Who Underwent Caesarean Delivery in Black Lion Specialized Hospital, Addis Ababa, Ethiopia. Ethiop J Health Sci.2018;28 (4):443.

doi:http://dx.doi.org/10.4314/ejhs.v28i4.10

Received: February 14, 2018

Accepted: February 20, 2018

Published: July 1, 2018

Copyright: (C) 2018 Adugna A. Kassa, et al. This is an open access article distributed under the terms of the Creative Commons Attribution License, which permits unrestricted use, distribution, and reproduction in any medium, provided the original author and source are credited.

Funding: Nil

Competing Interests: The authors declare that this manuscript was approved by all authors in its form and that no competing interest exists.

Affiliation and Correspondence:

${ }^{1}$ Department of Anesthesia College of Health Sciences Addis Ababa University Addis Ababa, Ethiopi

2Department of Anesthesia, Blac Lion Specialized Hospital, Addis Ababa, Ethiopia.

*Email: adugna.aregawi@aau.edu.et
ABSTRACT

BACKGROUND: Opinions are controversial regarding the use of general and spinal anesthesia in pre-eclamptic mothers undergoing Caesarean section. Some studies recommended avoiding spinal anesthesia in pre-eclamptic patients because of concern for sudden severe hypotension, while other studies support the use of spinal anesthesia as first choice reasoning less post-operative morbidity and mortality. This study aims to compare maternal outcome among pre-eclamptic women undergone caesarian delivery under general and spinal anesthesia.

METHODS AND PATIENTS: A retrospective comparative crosssectional study was conducted to compare maternal outcome. All pre-eclamptic mothers who underwent Caesarian section in Black Lion Specialized Hospital from October 2014 to October 2016 were included in the study. Data entry and analysis were conducted using SPSS version 20. Student's T-test was used to compare the outcome in both groups and $p$ value $<0.05$ was set as cut off point for statistical significance.

RESULTS: A total of 170 client documents were reviewed. The mean age of the study subjects was $28.18 \pm 4.66$ years, with median age 28 years (IQR: 25-30). Our study shows that both general and spinal anesthesia have no difference in terms of maternal survival status, days of hospital stay, post-operative admission to ICU, and post-operative complications. However, this study found a statistically significant higher post-operative blood pressure and pulse rate among general anesthesia groups compared with spinal anesthesia group.

CONCLUSION: Spinal anesthesia is safer than general anesthesia in terms of stable vital signs among pre-eclamptic women undergoing Cesarean section.

KEYWORDS: Spinal, General, Anesthesia, Pre-eclampsia, Maternal outcome 


\section{INTRODUCTION}

In Ethiopia, pre-eclampsia contributed to the complication of approximately $1 \%$ of all deliveries and $5 \%$ of all pregnancies. Moreover, $16 \%$ of direct maternal mortality and $10 \%$ of all maternal mortality (direct and indirect) was due to preeclampsia/eclampsia (1). Another maternal mortality trend analysis showed an increasing trend of pre-eclampsia in Ethiopia (2).

A medical interruption of pregnancy may be indicated in severe uncontrolled pre-eclampsia. Cesarean Section (CS) is one of the lifesaving surgical interventions contributing to decrement of maternal and fetal mortality and morbidity. The frequency of cesarean section deliveries continues to steadily rise worldwide (3). According to Demographic Health Survey, 1990-2014, the global cesarean section rate is $18.6 \%$. The average cesarean section rate in Africa is $7.3 \%$, the highest in Egypt $(51.8 \%)$ and $0.6 \%$ for Ethiopia which is the lowest (4).

Cesarean anesthesia has gained importance as the cesarean birth rates have increased. Even though the cesarean procedure has become very safe over the years, it is still associated with high rates of maternal and perinatal mortality and morbidity (5). The overall postoperative morbidity rate associated with cesarean births is $35.7 \%$. The higher mortality and morbidity rates might be attributable not only to the surgical procedure but also to the anesthetic technique preferred (6).

Women with pre-eclampsia have an increased rate of CS consequent upon the high incidence of intrauterine growth restriction, fetal distress and prematurity (7). Cesarean section on the other hand increases the risk of cardiopulmonary morbidity associated with pre-eclampsia (8). This is due to the altered hemodynamic in women with preeclampsia, particularly in an emergency situation. This risk is present with both spinal and general anesthesia (GA) and continues to challenge anesthetists worldwide (9).

Anesthetic management of pre-eclampsia patients remains a challenge. General anesthesia (GA) and spinal anesthesia (SA) have been shown to be acceptable and safe methods for conducting cesarean deliveries in pre-eclampsia, if steps are taken to ensure a careful approach to either technique (7). Although general anesthesia can be used in pre-eclampsia women, it is associated with greater maternal morbidity and mortality. The added risks associated with GA include airway difficulties due to edema (often aggravated by tracheal intubation) and the presser response to laryngoscopy and intubation (10).

Opinions are controversial regarding the use of spinal anesthesia in pre-eclamptic mothers undergoing CS. Several studies recommended avoiding spinal anesthesia in pre-eclamptic mothers because of concern for sudden severe hypotension $(11,12)$.

A fifteen years' (1996-2010) obstetric anesthesia trend analysis in an Ethiopian University Hospital determined that GA was still a predominant anesthetic technique (65.6\%) compared with SA (13). Considering the anesthetic dilemma and controversies among existing studies and limited studies on the the area, this study aimed to determine and compare maternal outcome among pre-eclamptic women following caesarian delivery under general and spinal anesthesia in Black Lion Specialized Hospital, Addis Ababa, Ethiopia.

\section{PATIENTS AND METHODS}

After approval was obtained from Addis Ababa University College of Health Sciences Ethical Review Committee and Black Lion Specialized Hospital Management, data of pre-eclamptic mothers who underwent CS in Obstetrics and Gynecology ward, Black Lion Specialized Hospital, from October 2014 to October 2016 were retrieved retrospectively from recording books and patient charts. Charts were coded and only accessed by research team. Confidentiality of participant records and privacy of the hospital was secured.

All mothers with severe pre-eclampsia who underwent CS from October 2014 to October 2016 were selected from the CS registration book, and their charts were collected from the card store. Using a structured check list, socio-demographic variables (age, weight, marital status), obstetric characteristics (gravity, parity, gestational age, ANC follow-up), pre-operative (Blood pressure,

DOI: http://dx.doi.org/10.4314/ejhs.v28i4.10 
pulse rate, medication type and dose, comorbidity), intra-operative (type of anesthesia, BP, $\mathrm{PR}, \mathrm{SpO} 2$, complications) and post-operative data (BP, PR, RR, any complication to the mother, length of hospital stay and ICU admission) were reviewed from the charts and documented.

The hemodynamic variables (HR and $\mathrm{BP}$ ) were documented at pre-anesthesia period, and intra-operatively at $5^{\text {th }}, 10^{\text {th }}, 20^{\text {th }}, 30^{\text {th }}$ and $60^{\text {th }}$ minutes after administration of either GA or SA. Hemodynamic instability was considered when there was a $25 \%$ change from the baseline value. Post-operative hospital stay was quantified in days from the day of the procedure till the patient discharge day. Patients were considered as having stable vital sign if their blood pressure and HR showed significant decrement after administration of anesthesia compared to their baseline values, as increase in BP and HR is a problem in preeclamptic mothers.

The collected data was cleaned, coded, entered into SPSS version 20 statistical software for analysis. Data were checked for completeness and consistency. Frequency tables and graphs were used to describe the study variables. Independent sample t-test was conducted to compare the difference in outcome between spinal and general anesthesia. $\mathrm{P}$ value $<0.05$ was considered statistically significant.

\section{RESULTS}

Out of charts of 208 mother with preeclampsia, 170 patients' documents were reviewed based on the eligibility criteria and completeness of the documents. The mean age of the study subjects was $28.18 \pm 4.66$ years; the median age was 28 years (IQR: 25-30). The majority of the cases, $134(78.8 \%)$, were from urban and the rest, 36(21.2\%), from rural areas. Regarding marital status, 153(96.8\%) were married while the the rest were unmarried.

Most of the study subjects were multiparous (55\%) while the remaining $45 \%$ were nulliparous. About 77\% had ANC follow-up during their pregnancy, and about $15 \%$ had previous history of CS. Regarding the clinical characteristics, most of the CS were performed as emergency. Magnesium sulfate was the most frequently used drug to control blood pressure for pre-eclamptic mothers (Table 1).

Table 1: Clinical Characteristics of Preeclamptic Women Underwent C/S at TikurAnbessa Specialized hospital, Addis Ababa, Ethiopia, from 2014 to 2016.

\begin{tabular}{llll}
\hline \multicolumn{2}{c}{ Clinical characteristics } & $\begin{array}{l}\text { GA } \\
\mathrm{n}(\%)\end{array}$ & $\begin{array}{l}\mathrm{SA} \\
\mathrm{n}(\%)\end{array}$ \\
\hline Type of C/S & Elective & $5(3 \%)$ & $12(7 \%)$ \\
& Emergency & $75(44 \%)$ & $78(46 \%)$ \\
Operator status & Senior & $14(8.2 \%)$ & $14(8.2 \%)$ \\
& Resident or GP & $60(35.3 \%)$ & $72(42.3 \%)$
\end{tabular}

Note: Data are presented as frequency (percentages)

Abbreviations: GA, General anesthesia; SA, Spinal anesthesia; C/S, Cesarean section; $\quad$ GP, General practitioner; n, frequency

DOI: http://dx.doi.org/10.4314/ejhs.v28i4.10 
The majority (53.5\%) of CS cases were performed using SA. There were no documented maternal deaths and no significant difference was observed between GA and SA regarding days of hospital stay.

There was no significant difference among the groups with regard to heart rate (HR) and blood pressure (BP) at ward and before administration of anesthesia. However, the mean $\mathrm{HR}$ and BP was significantly higher in GA groups compared to SA groups after anesthesia was administered throughout the intraoperative period (Table 2, Figures 1-3).

Table 2: Comparison of Maternal Pulse Rate and Blood Pressure among Preeclamptic Women Underwent C/S under GA and SA at TikurAnbessa Specialized hospital, Addis Ababa, Ethiopia, from 2014 to 2016

\begin{tabular}{|c|c|c|c|c|c|}
\hline \multicolumn{2}{|c|}{ Variables } & GA groups & SA groups & $\begin{array}{l}95 \% \text { CI of mean } \\
\text { difference }\end{array}$ & p-value \\
\hline \multirow{6}{*}{ 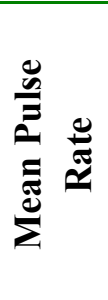 } & Before anesthesia & $98.97(7.5)$ & $95.66(8.9)$ & $3.32(-0.64-7.3)$ & $0.09 *$ \\
\hline & $5^{\text {th }}$ minute after aesthesia & $103.20(10.6)$ & $92.83(12.3)$ & $10.36(4.10-16.6)$ & 0.002 \\
\hline & $10^{\text {th }}$ minutes & $99.60(9.6)$ & $88.93(9.7)$ & $10.73(7.70-13.7)$ & $<0.001$ \\
\hline & $20^{\text {th }}$ minutes & $96.00(8.5)$ & $84.00(9.2)$ & $11.53(8.7-14.3)$ & $<0.001$ \\
\hline & $30^{\text {th }}$ minutes & $93.12(6.9)$ & $82.62(8.7)$ & $7.90(5.90-10.1)$ & $<0.001$ \\
\hline & $60^{\text {th }}$ minutes & $90.05(5.8)$ & $82.67(7.0)$ & $7.38(5.40-9.4)$ & $<0.001$ \\
\hline \multirow{6}{*}{ 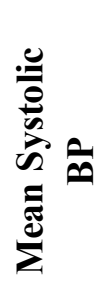 } & Before anesthesia & $154.54(19.4)$ & $151.23(12.4)$ & $3.31(-0.40-10.7)$ & $0.37 *$ \\
\hline & $5^{\text {th }}$ minute after anesthesia & $162.70(14.0)$ & $144.30(15.7)$ & $15.10(5.92-24.3)$ & 0.002 \\
\hline & $10^{\text {th }}$ minutes & $157.80(12.7)$ & $137.70(13.3)$ & $20.00(16.00-24.2)$ & $<0.001$ \\
\hline & $20^{\text {th }}$ minutes & $148.90(11.3)$ & $127.60(12.6)$ & $21.38(17.60-25.1)$ & $<0.001$ \\
\hline & $30^{\text {th }}$ minutes & $141.50(11.9)$ & $119.60(13.0)$ & $21.88(17.90-25.7)$ & $<0.001$ \\
\hline & $60^{\text {th }}$ minutes & $134.70(9.6)$ & $122.70(10.5)$ & $12.00(8.9-15.1)$ & $<0.001$ \\
\hline \multirow{6}{*}{ 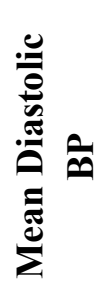 } & Before anesthesia & $97.64(7.7)$ & $92.54(9.2)$ & $5.10(-1.33-8.9)$ & $0.09^{*}$ \\
\hline & $5^{\text {th }}$ minute after anesthesia & $96.54(18.7)$ & $88.76(8.8)$ & $7.78(0.6-15.5)$ & 0.035 \\
\hline & $10^{\text {th }}$ minute & $92.77(12.7)$ & $81.40(8.9)$ & $11.37(8.74-14.0)$ & $<0.001$ \\
\hline & $20^{\text {th }}$ minute & $86.50(6.3)$ & $73.07(8.6)$ & $13.49(11.09-15.9)$ & $<0.001$ \\
\hline & $30^{\text {th }}$ minute & $82.18(9.7)$ & $67.63(8.4)$ & $14.55(11.74-17.4)$ & $<0.001$ \\
\hline & $60^{\text {th }}$ minute & $78.24(11.2)$ & 71.64(11.3) & $6.60(3.13-10.1)$ & $<0.001$ \\
\hline
\end{tabular}

Note: Data are presented as mean (SD)

Abbreviations: BP,blood pressure; GA, General anesthesia; SA, Spinal anesthesia; CI, confidence interval

$*=$ not statistically significant

DOI: http://dx.doi.org/10.4314/ejhs.v28i4.10 


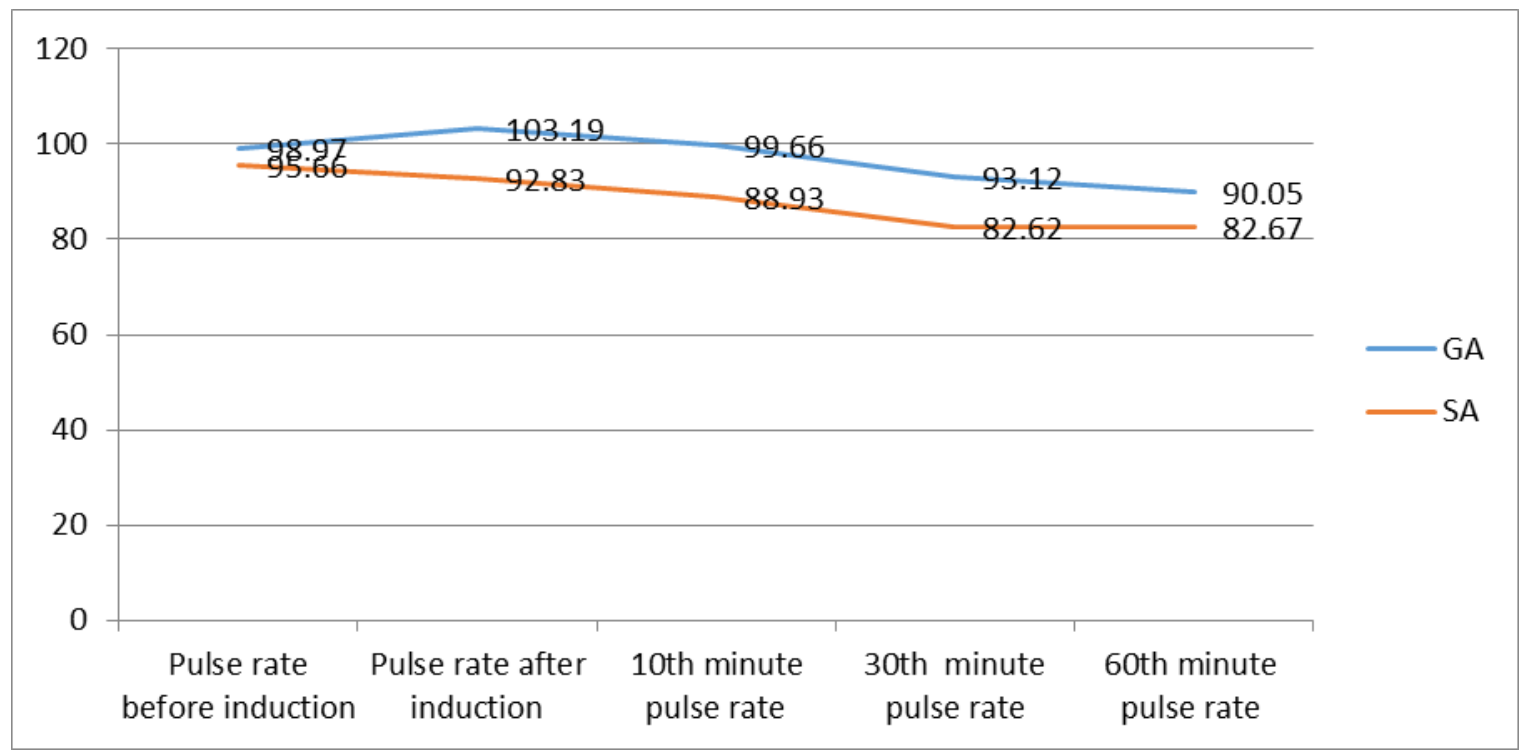

Figure 1: Comparison of pulse rate of preeclamptic women who underwent CS at Black Lion Specialized Hospital, Addis Ababa, Ethiopia, from 2014 to 2016

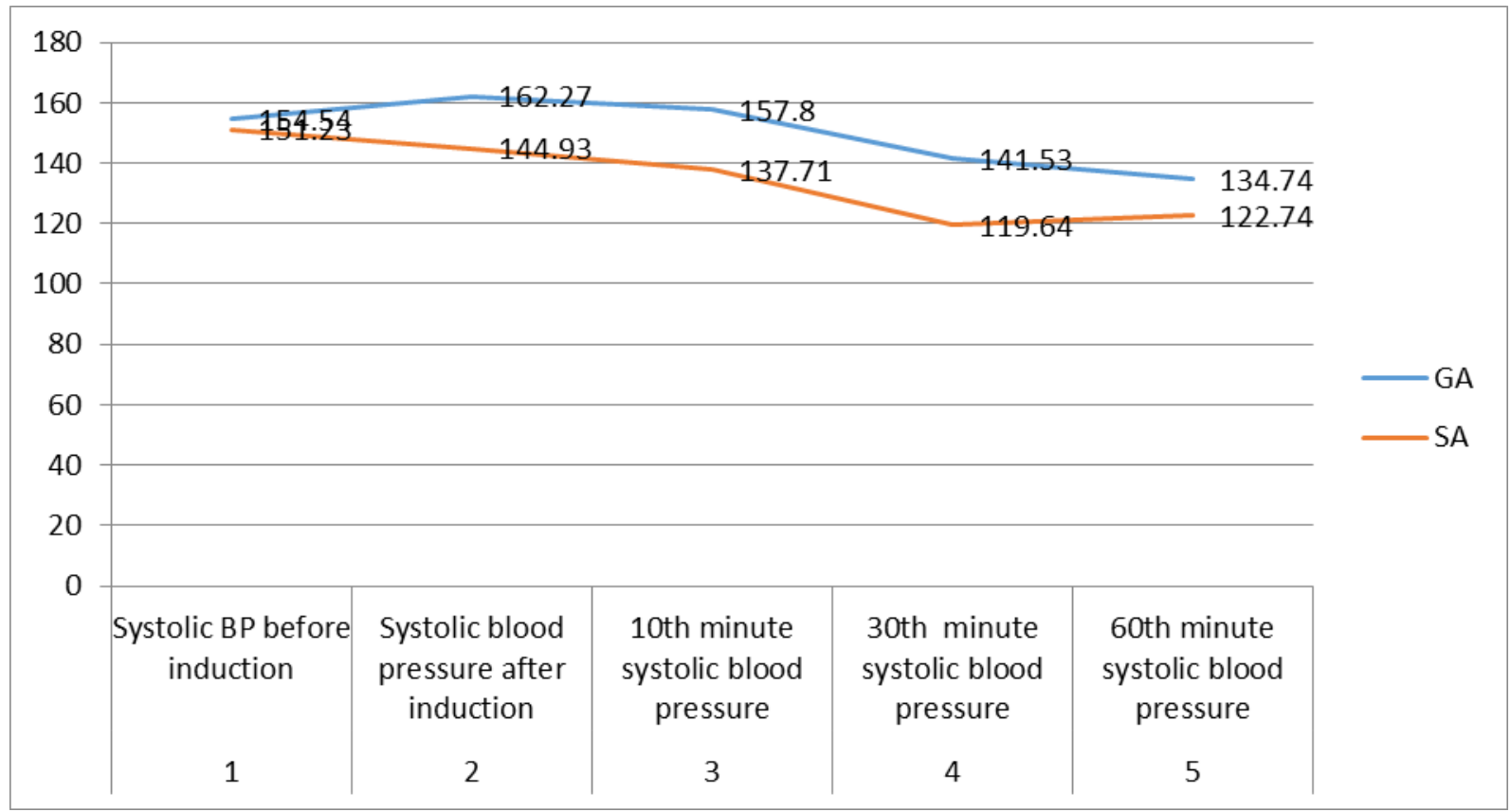

Figure 2: Comparison of mean systolic BP of preeclamptic women who underwent CS at Black Lion Specialized Hospital, Addis Ababa, Ethiopia, from 2014 to 2016

DOI: http://dx.doi.org/10.4314/ejhs.v28i4.10 


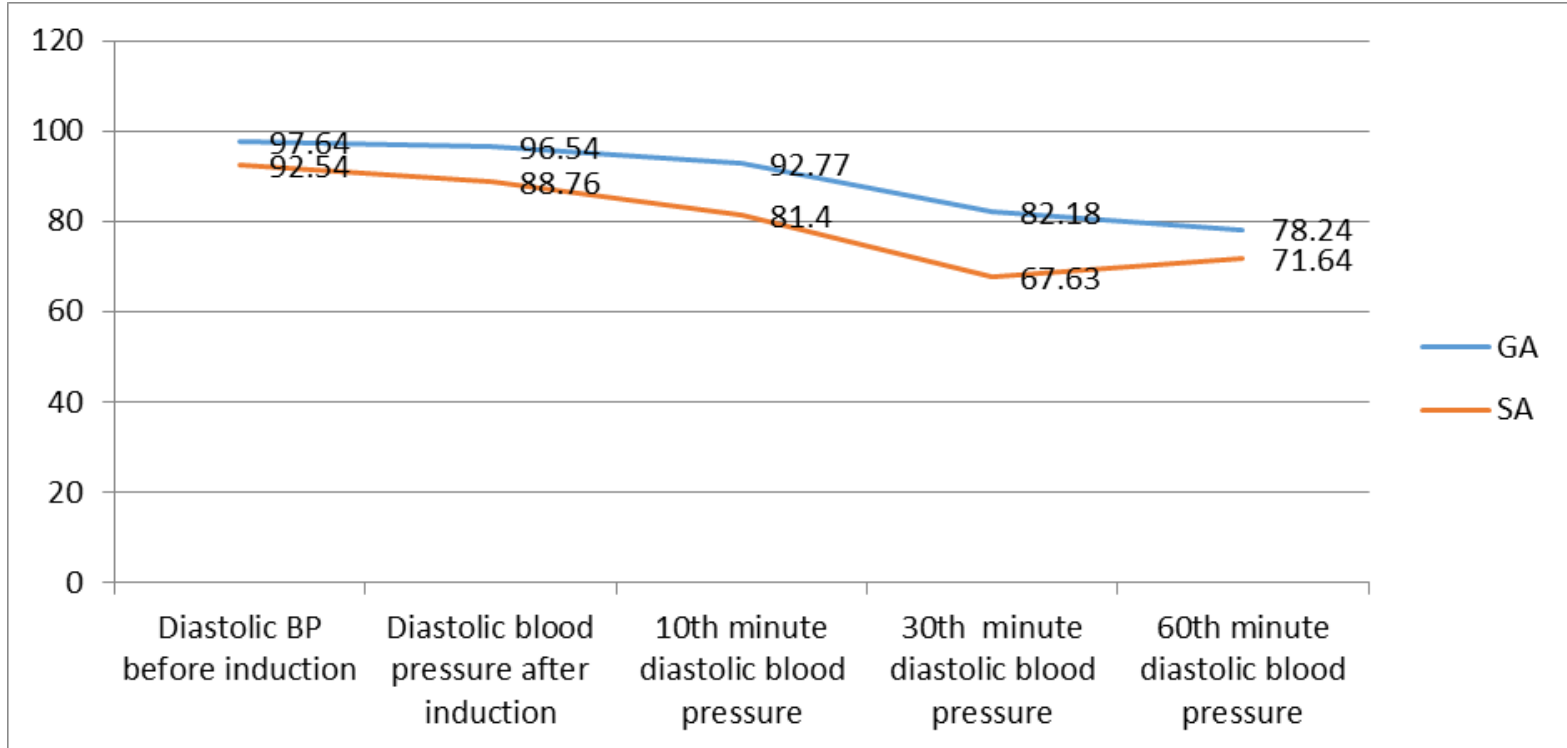

Figure 3: Comparison of mean diastolic BP of preeclamptic women who underwent CS at Black Lion Specialized Hospital, Addis Ababa, Ethiopia, from 2014 to 2016

\section{DISCUSSION}

In this retrospective comparative cross-sectional study, a total of 170 clients' cards were reviewed. Nearly $53 \%$ of these clients with severe preeclampsia underwent their operation under SA and the remaining took GA. The mean ages of the respondents were comparable between general and spinal anesthesia groups (28.2 Vs 28.1) respectively. The mean pulse rate, systolic blood pressure and diastolic blood pressure before administration of anesthesia had no statistically significant differences $(p>0.05)$.

This study revealed that spinal anesthesia is superior to general anesthesia for pre-eclamptic mothers in terms of stable hemodynamic status in the intraoperative period. The mean heart rate and blood pressure of mothers who underwent CS under GA was higher than the normal values throughout the intraoperative period, while these vital signs decreased to the normal range throughout the intraoperative period once SA had been administered. This finding is in line with previous studies conducted in different regions of the world (9,13-15). Systemic vasodilation induced by sympathetic blockade after SA, resulting in venous pooling of blood and reduction in systemic vascular resistance, has been regarded as the predominant mechanism for reduced blood pressure (16). The blockade of cardio accelerator sympathetic fibers at the first to fourth (T1 to T4) nerve roots, and possibly the "reverse" of the Bainbridge (atrial) reflex is believed to be the cause for decrement in heart rate following administration of SA. Bainbridge reflex, also called atrial reflex, is increment of the heart rate resulting from distension of large systemic veins or the right atrium (17). The hypotensive and bradycardia effect of SA is the undesirable effect in nonpre-eclamptic population. However, in our study, we found out that SA decreased the heart rate and blood pressure only to the desired level, acting as an antihypertensive agent to preeclamptic mothers in addition to its well established advantages over GA regarding safe airway, improved postoperative analgesia, reduced risk of airway obstruction or aspiration, decreased blood loss, less immune suppression, less cognitive impairment (especially in the elderly), reliable and excellent intra-operating conditions, less costly usage, decreased incidence of deep vein thrombosis and pulmonary emboli formation $(15,18,19)$.

This study did not find a significant difference regarding maternal outcome and days of hospital stay between the groups. Although

DOI: http://x.doi.org/10.4314/ejhs.v28i4.10 
some studies showed similar findings with that of ours (3), some others reported better outcome in terms of morbidity and mortality, days of hospital stay and rates of post-operative ICU admission in patients who received SA compared to GA $(9,14)$. The reason our study could not find a difference regarding maternal outcome between the two groups may be due to inadequate sample size in our study to detect a difference in such relatively rare complications.

This study used secondary data from medical records of the patients. The information stated in this document is limited to data that is only available in the individual medical records. Therefore, it was hardly possible to find further information than that is recorded in the individual medical record.

In conclusion, in this study, significantly higher intra-operative blood pressure and pulse rate was observed among GA group than SA. Therefore, SA is safer than GA in terms of stable vital signs among pre-eclamptic women.

\section{REFERENCES}

1. Gaym A, Bailey P, BLuwei P, Admasu K, Gebrehiwot Y. Disease burden due to preeclampsia/eclampsia and the Ethiopian health system's response. Int $J$ Gynecol Obstet. 2011;115:112-6.

2. Abdella A. Maternal mortality trend in Ethiopia. Ethiop J Health Dev. 2010; 24(1):115-22.

3. Gori F, Pasqualucci A, Coradetti F, Milli M \& Peduto VA. Maternal and neonatal outcome after cesarean section: the impact of anesthesia. J Maternal Fetal Neonatal Med. 2007; 20(1): 53-7.

4. Betrán AP, Ye J, Moller A-B, Zhang J, Gülmezoglu M \& Torloni MR. The Increasing Trend in Caesarean Section Rates: Global, Regional and National Estimates: 1990-2014. PLoS ONE.2016; 11(2).

5. Liu S, Liston RM, Joseph KS, Heaman M, Sauve R, Kramer MS. Maternal mortality and severe hypertension associated with low-risk planned cesarean delivery versus planned vaginal delivery at term. CMAJ, 2007; 176 (4):455-60.

6. Sayg1 AI, Ozdamar O, Gun I, Emirkadı H, Mungen E, Akpak YK. Comparison of maternal and fetal outcomes among patients undergoing cesarean section under general and spinal anesthesia: a randomized clinical trial. Sao Paulo Med J. 2015; 133(3):227-34.

7. Polley LS: Hypertensive disorders, in Chestnut's Obstetric Anesthesia: Principles and Practice, D. H. Chestnut, L. S. Polley, L.C.Tsen, and C.A.Wong, Eds., pp. 9751008,Mosby Elsevier, Philadelphia, Pa, USA, 4th edition, 2009.

8. Terrone DA, Isler CM, May WL, Magann EF, Norman PF, Martin JN Jr. Cardiopulmonary morbidity as a complication of severe preeclampsia, HELLP syndrome. $J$ Perinatol. 2000; 20(2):78-81.

9. Chattopadhyay S, Das A, Pahari S. Fetomaternal Outcome in Severe Preeclamptic Women Undergoing Emergency Cesarean Section under either General or Spinal Anesthesia. J pregnancy. 2014; Vol. 2014, Article ID 325098, 10 pages.

10. Mandal NG, Surapaneni S. Regional Anesthesia in pre-eclampsia: advantages and disadvantages. Drugs. 2004; 64(3):223-36.

11. Sharma KR, Shrestha ZA. Spinal Anesthesia for Cesarean section in Preeclampsia. Postgraduate medical journal of NAMS 2012; $12(2)$

12. Zahid HK. Preeclampsia/Eclampsia; An insight into the Dilemma of Treatment by the Anesthesiologist. Acta Medica Iranica.2011; 49 (9).

13. Zewditu A, Tadesse A, Tadesse B, Mulat A. Trends in Obstetrics Anesthesia, at Gondar University Hospital. EC Anaesthesia. 2015; 2 (2): 99-105.

14. Ravi T, Kumar ND, Raju K. Analysis of maternal outcome of general versus spinal anesthesia for caesarean delivery in severe pre-eclampsia. Asian Pac. J. Health Sci., 2016; 3 (3):101-107

15. Pacharla I, Rajola R, Kota R,M.Chandra S. Analysis of Maternal Outcomes in Severe PreEclampsia Patients under General versus 
Spinal Anaesthesia for Caesarean Delivery. IOSR Journal of Dental and Medical Sciences, 2016; 15(2): 33-39.

16. Neal JM. Hypotension and bradycardia during spinal anesthesia: Significance, prevention, and treatment. Tech Reg Anesth Pain Manag. 2000; 4(4): 148-54.

17. Crystal GJ, Salem MR. The Bainbridge and the "reverse" Bainbridge reflexes: History, physiology, and clinical relevance. Anesth Analg. 2012;114(3):520-532.

18. Qublan HS, Merhej A, Dabbas MA, Hindawi IM. Spinal versus general anesthesia for elective cesarean delivery: a prospective comparative study. Clin Exp Obstet Gynecol.2001; 28(4):246-8.

19. Movasseghi G, Hassani V, Mohaghegh MR, Safaeian R, Safari S, Zamani MM, and Nabizadeh R. Comparison between Spinal and General Anesthesia in Percutaneous Nephrolithotomy. Anesth Pain Med. 2014; 4(1):1-6. 